\title{
Patterns of C-2 fracture in the elderly: comparison of etiology, treatment, and mortality among specific fracture types
}

\author{
Ingrid Radovanovic, MD, , Jennifer C. Urquhart, PhD, ,2,3 Parham Rasoulinejad, MD, ${ }^{1-3}$ \\ Kevin R. Gurr, MD, ${ }^{1-3}$ Fawaz Siddiqi, MD, ${ }^{1-3}$ and Christopher S. Bailey, MD, MSc ${ }^{1-3}$ \\ 1Division of Orthopaedics, Department of Surgery, Schulich School of Medicine and Dentistry, The University of Western Ontario; \\ 'Lawson Health Research Institute; and ' ${ }^{2}$ ondon Health Sciences Center, London, Ontario, Canada
}

\begin{abstract}
OBJECTIVE Previous studies have focused on Type II odontoid fractures and have failed to report on the effect of other $\mathrm{C}-2$ fracture types on treatment and outcome. The purpose of this study was to compare patient characteristics, cause of injury, predisposing factors to fracture, treatments, and mortality rates among C-2 fracture types in a cohort of elderly patients 70 years of age and older.
\end{abstract}

METHODS A retrospective cohort study design was used. Patients who sustained a C-2 fracture between 2002 and 2011 and who were admitted to the authors' Level 1 trauma center were identified using the Discharge Abstract Database and the International Statistical Classification of Diseases and Related Health Problems (ICD-10) code S12.1. Fractures were classified as odontoid Type I, II, or III; hangman's; C-2 complex (hangman's appearance on sagittal images, Type III odontoid on coronal cuts); and other (miscellaneous). Age, sex, predisposing factors to falls, cause of injury, treatment, presence of autofusion in the subaxial cervical spine, and mortality rates were compared between fracture patterns.

RESULTS One hundred forty-one patients were included; their mean age was 82 years. Fractures included Type II odontoid (57\%), complex (19\%), Type III odontoid (11\%), hangman's ( $8 \%)$, and other $(5 \%)$. Falls from a standing height accounted for $47 \%$ of injuries, and $65 \%$ of patients had $\geq 3$ risk factors for falls. Subaxial autofusion was more common in odontoid fractures $(p=0.002)$. Treatment was mainly nonoperative $(p<0.0001)$. The 1 -year mortality rate was $27 \%$. Four patients died of spinal cord injury.

CONCLUSIONS Although not as common as Type II odontoid fractures, other C-2 fractures including hangman's, complex, and Type III odontoid fractures accounted for close to half of the injuries in the study cohort. There were few differences between the fracture types with respect to cause of injury, predisposing factors, or mortality rate. However, surgical treatment was more common for Type Il odontoid fractures.

https://thejns.org/doi/abs/10.3171/2017.3.SPINE161176

KEY WORDS cervical spine; fracture; demographics; geriatric; autofusion; mortality rate; trauma

$\mathrm{E}$ LDERLY patients have a higher prevalence of cervical spine fractures, including $\mathrm{C}-2$ fractures in particular, than any other age group, and the occurrence of these fractures is on the rise. ${ }^{19}$ A recent study of the Medicare population revealed that the incidence of C-2 fractures increased by 135\% from 2000 to 2011 among persons 65 years of age and older. Currently $10 \%-12 \%$ of North Americans are 70 years of age and older, and by 2030 this proportion is expected to double. ${ }^{1,25}$ With an increasing life expectancy, a more active elderly population, and higher rates of diagnosis, surgeons face the difficulty of encountering and treating these fractures on a more regular basis.

Cervical spine fractures in the elderly commonly occur following a simple fall from standing height. ${ }^{17}$ They can be a devastating injury, with a mortality rate upwards of 24\%-26\%.6,17,24 Traditionally, C-2 fractures have been treated by ridged cervical collar application, halo bracing, or surgical treatment. $5,7,16,20,22$ However, management options are still controversial. . $7,18,23$ Type II odontoid fractures are recognized to be the most common cervical spine injury in patients over the age of 70 years. ${ }^{3,6,13,14,17,22,28}$ Ac- 
TABLE 1. Inclusion and exclusion criteria

\begin{tabular}{ll}
\hline Inclusion Criteria & \multicolumn{1}{c}{ Exclusion Criteria } \\
\hline Age $\geq 70$ yrs & Incomplete radiographic studies to assess fracture type \\
\hline Acute C-2 fracture & Presenting with a chronic fracture nonunion as opposed to an acute fracture \\
\hline & Previous upper cervical spine surgical instrumentation \\
\hline & Has a pathological fracture \\
\hline & Noncontiguous spine trauma \\
\hline
\end{tabular}

cordingly, the majority of previously published literature regarding upper cervical spine fractures in the elderly has focused on Type II odontoid fractures. Those studies that have considered other types of $\mathrm{C}-2$ fractures have done so using a subanalysis of a heterogeneous cohort, and have consisted of a relatively small sample size..$^{5,12,18,23}$ Therefore, little is known about the association of specific C-2 fracture types with patient characteristics, risk factors, treatment, and outcome.

The objectives of this study were 2-fold: 1) to describe the distribution of C-2 fractures in a cohort of patients over the age of 70 years, and 2) to identify the association between fracture pattern and age, sex, risk factors, mechanism of injury, radiographic findings, treatment, and mortality rate.

\section{Methods}

Patients who were admitted to the London Health Sciences Centre between 2002 and 2011 with an acute C-2 fracture were retrospectively identified using the Discharge Abstract Database and the International Statistical Classification of Diseases and Related Health Problems (ICD-10) code S12.1. Patients who were 70 years of age or older were included. Exclusion criteria were incomplete radiographic studies to assess fracture type, presentation with a chronic fracture nonunion as opposed to an acute fracture, previous upper cervical spine surgical instrumentation, noncontiguous spine trauma, and a pathological fracture (Table 1). Approval was obtained from our institutional research ethics board.

Imaging was retrospectively reviewed independently by 2 fellowship-trained orthopedic spine surgeons. Fracture classification was determined using sagittal and coronal CT reconstructions. Fractures were classified as an odontoid Type I (tip of the odontoid), Type II (base of the odontoid), or Type III (fracture extending into the body of the odontoid) fracture as per Anderson and D'Alonzo; ${ }^{2}$ hangman's fracture as per the Levine classification; ${ }^{9}$ or as "other fractures," which included isolated lateral mass fractures and vertebral body avulsion fractures. During the classification process we identified several fractures that would be best classified as a hangman's fracture on the CT sagittal images (based on the presence of pars/lateral mass fractures) and a Type III odontoid fracture on the CT coronal images (based on a fracture extending through the vertebral body below the neck of the odontoid process). Because it was difficult to ascertain which classification best fit this biplanar fracture, we elected to call this group "C-2 complex" (Fig. 1). Any discrepancy in classification was resolved by consensus, with input from a third author.
Each patient's hospital chart was retrospectively reviewed to gather the following information: patient demographics, medical history, medications at the time of the fracture, cause of injury, operative versus nonoperative treatment, and cause of death. The treatment selected was chosen according to the surgeon's discretion on a patientby-patient basis without study-defined selection criteria.

Cause of injury was grouped as follows: fall from a standing height, fall downstairs, motor vehicle collision, other, or unknown. To assess the mortality rate, the survival status (alive, deceased, or unknown) for each patient was determined at 1 year after injury. For patients who died, the cause of death was descriptively reported according to the fracture classification group.

Patient risk factors for falls were assessed according to the WHO. ${ }^{27}$ We elected to focus on the 5 factors that could be reliably extracted from the hospital chart: age older than 80 years; female sex; specific medical history (circulatory disease, chronic obstructive pulmonary disease, depression, impaired cognition and vision, and arthritis); specific medications at admission (psychotropic, sedatives, diuretics, and so on); or taking more than 4 prescribed medications at admission. The CT images were further assessed for associated contiguous and noncontiguous subaxial autofusion spanning either single or multiple levels. The percentage of patients who had subaxial autofusion was determined for each C-2 fracture classification to determine if this risk factor for $\mathrm{C}-2$ fracture was similar between groups.

The data analysis was performed using PASW Statistics, version 20 (IBM SPSS, Inc.). The mean and SD values were used to describe continuous parametric variables, and comparisons were made between fracture groups by using 1-way ANOVA for age and the KruskalWallis test for follow-up duration. Percentages were used to describe categorical variables, and comparisons were made between fracture groups by using the Fisher's exact test with Monte Carlo approximation set to include 10,000 observations. For post hoc analysis, each fracture type was compared with all the other fracture types combined (i.e., Type II odontoid versus C-2 complex, Type III, hangman's, and other fracture pattern groups), complete case analysis was used, and $p$ values were adjusted to $p=0.01$ using the Bonferroni method for multiple comparisons. All $\mathrm{p}$ values were considered significant if $<0.05$, unless stated otherwise.

\section{Results}

A total of 674 patients were initially identified by database search as having a cervical spine fracture. Of these 

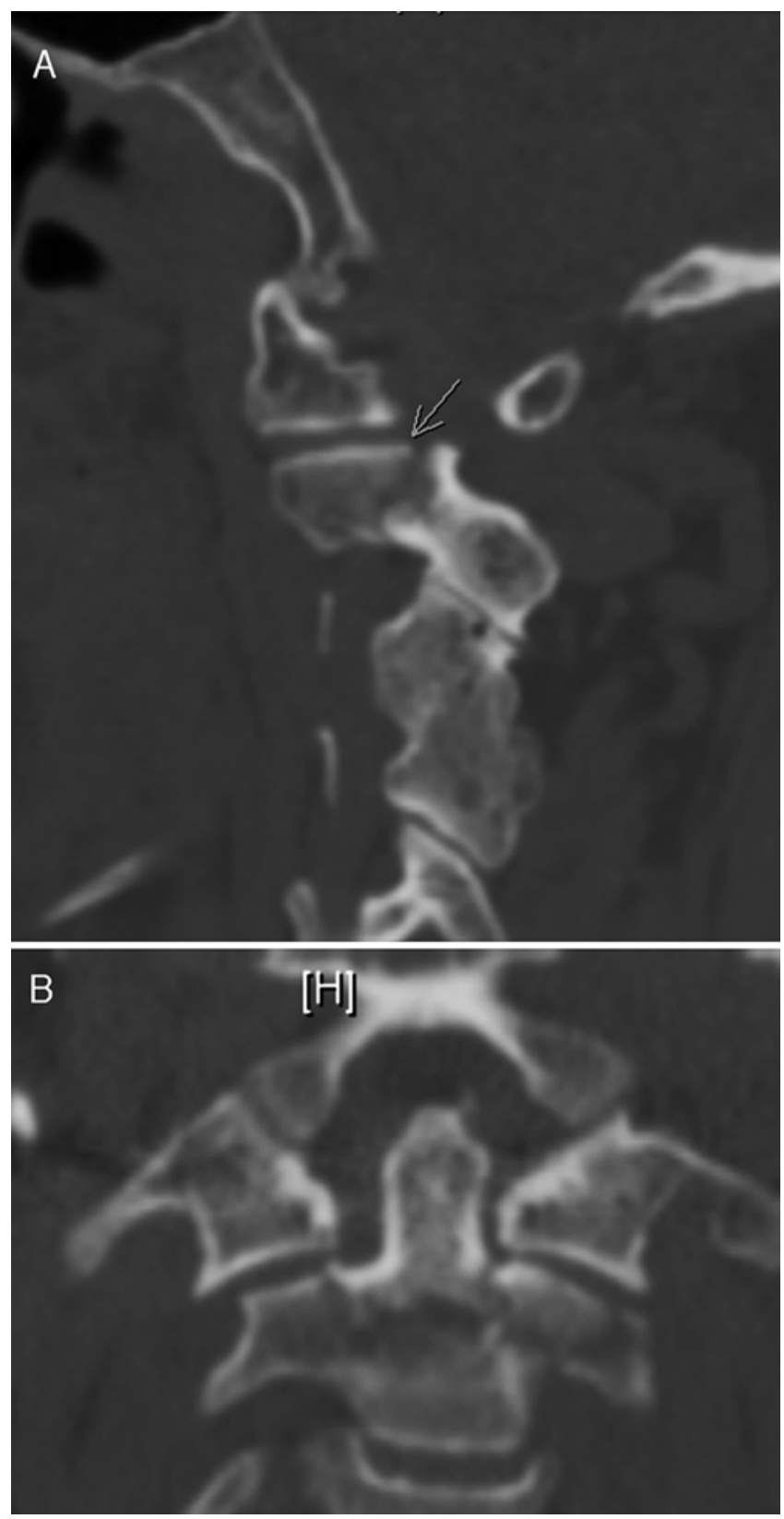

FIG. 1. Sagittal and coronal CT reconstructions showing examples of a complex $\mathrm{C}-2$ fracture. A: The sagittal image demonstrates the pars fracture (arrow), which is typical of a hangman's type fracture. Also note the autofusion that has occurred between the posterior elements of C-3 and C-4. B: The coronal image demonstrates the fracture extending through the body of $\mathrm{C}-2$ below the neck of the odontoid process. Fracture patterns that demonstrated this biplanar configuration were named complex fractures.

cases, 367 had a C-2 fracture, and 188 were 70 years of age or older $(188 / 367=51.2 \%)$. A total of 141 patients satisfied all the inclusion and exclusion criteria and were included in the study for analysis. Of these 141 patients, the most common fracture pattern was Type II odontoid fractures (57\%; Table 2). This was followed by C-2 complex fractures (19\%), Type III odontoid fractures (11\%), and hangman's fractures (8\%). Of the hangman's fractures subgroup, 91\% were Type I fractures, which means they
TABLE 2. Fracture pattern distribution in 141 patients

\begin{tabular}{lc}
\hline \multicolumn{1}{c}{ Fracture Pattern } & No. of Patients (\%) \\
\hline Type II odontoid & $81(57.4)$ \\
\hline C-2 complex & $27(19.1)$ \\
\hline Type III odontoid & $15(10.6)$ \\
\hline Hangman's & $11(7.8)$ \\
\hline Other & $3(2.1)$ \\
\hline Lateral mass fracture & $2(1.4)$ \\
\hline Inferior anterior body avulsion & $1(0.7)$ \\
\hline Transverse process fracture & $1(0.7)$ \\
\hline Spinous process fracture
\end{tabular}

were nondisplaced fractures. Approximately $5 \%$ of the patients were classified into the "other" fracture group, having sustained fracture patterns such as a lateral mass fracture (2\%), extension type vertebral body avulsion fracture $(1 \%)$, transverse process fracture $(1 \%)$, or spinous process fracture (1\%). Initial agreement on fracture type occurred between the 2 reviewers in all but 14 cases (10\%). These 14 cases were reviewed together and consensus was reached as to the classification type. Patients were followed on average for 6 months (Table 3).

Patient demographics are listed in Table 3. The mean age of the overall study population was $82 \pm 4$ years (mean $\pm \mathrm{SD})$. Age did not differ between fracture patterns $(\mathrm{p}=$ 0.597 ). In the overall study population, $\mathrm{C}-2$ fractures were equally common in both sexes $(48 \%$ were in male patients and $52 \%$ were in females). However, there was a difference in sex ratios between fracture pattern groups $(\mathrm{p}=$ 0.022). Whereas Type II odontoid, Type III odontoid, and hangman's fractures were equally common in males and females, the majority of patients who suffered a C-2 complex fracture were female ( $p<0.009$; C-2 complex vs all other groups combined). Compared with all the fracture groups combined, there tended to be more male patients who suffered an "other" C-2 fracture type (85\%), but this finding was not significant after adjustment for multiple comparisons $(\mathrm{p}>0.01)$.

Falls accounted for the majority of injuries for all fracture groups. In the overall cohort 66 of 141 patients (47\%) were injured by a fall from standing height, and 17/141 patients (12\%) fell down stairs. Only 15/141 (11\%) were involved in motor vehicle collisions. There was no difference in the cause of injury between the fracture patterns $(\mathrm{p}=0.161)$. However, for $40 / 141$ patients $(28 \%)$ the cause of injury was undocumented.

In the overall cohort, the majority of patients had 3 or more risk factors for a fall. No fracture group had more predisposing risk factors for falls than any other fracture group ( $\mathrm{p}=0.513)$. However, for $34 / 141(24 \%)$ of the cohort, the number of risk factors for a fall was unknown due to the patient's medical records being incomplete.

Subaxial autofusion occurred in 57\% of patients who suffered a Type II odontoid fracture and in $60 \%$ of patients who suffered a Type III odontoid fracture. In contrast, only $37 \%, 27 \%$, and $14 \%$ of patients in the C-2 complex fracture, hangman's fracture, and other fracture groups, respectively, had autofusion (Fig. $2 ; \mathrm{p}=0.030$ ). Post hoc 
TABLE 3. Comparison of demographics according to fracture classification in 141 patients

\begin{tabular}{|c|c|c|c|c|c|c|c|}
\hline Characteristic & Overall Cohort & Type II Odontoid & C-2 Complex & Type III Odontoid & Hangman's & Other & p Value \\
\hline No. of patients & 141 & 81 & 27 & 15 & 11 & 7 & \\
\hline Age in yrs, mean $\pm S D$ & $82.4 \pm 4.4$ & $82.6 \pm 6.3$ & $81.3 \pm 7.0$ & $83.4 \pm 5.3$ & $80.6 \pm 7.3$ & $84.6 \pm 9.8$ & 0.597 \\
\hline Female sex & $73(51.8)$ & $39(48.1)$ & $20(74.1)$ & $6(40.0)$ & $7(63.6)$ & $1(14.3)$ & 0.022 \\
\hline Cause of Injury & & & & & & & 0.161 \\
\hline Fall-standing & $66(46.8)$ & $43(53.1)$ & $6(22.2)$ & $8(53.3)$ & $4(36.4)$ & $5(71.4)$ & \\
\hline Fall-stairs & $17(12.1)$ & $10(12.3)$ & $3(11.1)$ & $2(13.3)$ & $2(18.2)$ & $0(0)$ & \\
\hline Motor vehicle collision & $15(10.6)$ & $5(6.2)$ & $5(18.5)$ & $3(20.0)$ & $2(18.2)$ & $0(0)$ & \\
\hline Other & $3(2.1)$ & $1(1.2)$ & $2(7.4)$ & $0(0)$ & $0(0)$ & $0(0)$ & \\
\hline Unknown & $40(28.4)$ & $22(27.2)$ & $11(40.7)$ & $2(13.3)$ & $3(27.3)$ & $2(28.6)$ & \\
\hline No. of risk factors for a fall ${ }^{\star}$ & & & & & & & 0.513 \\
\hline$\leq 2$ & $15(10.6)$ & $6(7.4)$ & $5(18.5)$ & $2(13.3)$ & $1(9.1)$ & $1(14.3)$ & \\
\hline 3 & $23(16.3)$ & $15(18.5)$ & $3(11.1)$ & $0(0)$ & $4(36.4)$ & $1(14.3)$ & \\
\hline 4 & $47(33.3)$ & $25(30.9)$ & $8(29.6)$ & $8(53.3)$ & $3(27.3)$ & $3(42.9)$ & \\
\hline 5 & $22(15.6)$ & $16(19.7)$ & $4(14.8)$ & $2(13.3)$ & $0(0.0)$ & $0(0.0)$ & \\
\hline Unknown & $34(24.1)$ & $19(23.5)$ & $7(25.9)$ & $3(20.0)$ & $3(27.3)$ & $2(28.6)$ & \\
\hline Treatment & & & & & & & $<0.001$ \\
\hline Op & $39(27.6)$ & $33(40.7)$ & $3(11.1)$ & $0(0.0)$ & $3(27.3)$ & $0(0.0)$ & \\
\hline Nonop & $88(62.4)$ & $44(54.3)$ & $21(77.8)$ & $13(86.7)$ & $7(63.6)$ & $3(42.9)$ & \\
\hline Death before treatment & $8(5.7)$ & $3(3.7)$ & $1(3.7)$ & $1(6.7)$ & $0(0.0)$ & $3(42.9)$ & \\
\hline Unknown & $6(4.3)$ & $1(1.2)$ & $2(7.4)$ & $1(6.7)$ & $1(9.1)$ & $1(14.3)$ & \\
\hline 1-yr survival status & & & & & & & 0.186 \\
\hline Alive & $78(55.3)$ & $40(49.4)$ & $20(74.1)$ & $7(46.7)$ & $8(72.7)$ & $3(42.9)$ & \\
\hline Deceased & $38(27.0)$ & $25(30.9)$ & $4(14.8)$ & $4(26.7)$ & $1(9.1)$ & $4(57.1)$ & \\
\hline Unknown & $25(17.7)$ & $16(19.7)$ & $3(11.1)$ & $4(26.7)$ & $2(18.2)$ & $0(0)$ & \\
\hline Follow-up duration, days & & & & & & & 0.115 \\
\hline Mean \pm SD & $170 \pm 292$ & $108 \pm 89$ & $216 \pm 364$ & $93 \pm 95$ & $165 \pm 233$ & $46 \pm 79$ & \\
\hline Median; range & $90 ; 0-2247$ & $93 ; 0-459$ & $97 ; 0-2247$ & $76 ; 0-314$ & $118 ; 5-844$ & $24 ; 0-233$ & \\
\hline
\end{tabular}

Unless otherwise indicated, values are expressed as the number of patients (\%).

* Risk factors for fall include age over 80 years, female sex, past medical history, medications at admission, or taking more than 4 prescribed medications at admission.

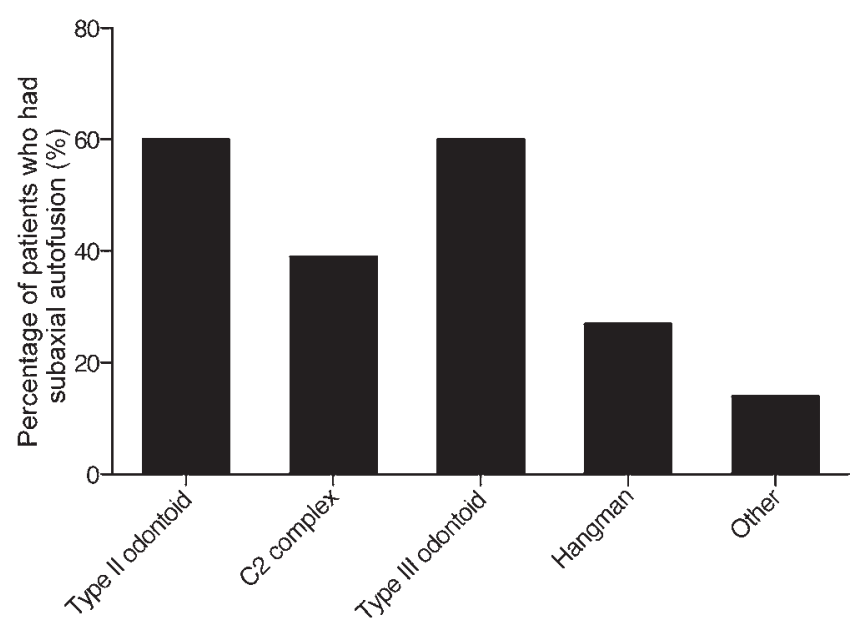

FIG. 2. Bar graph showing that subaxial autofusion was significantly more common in patients who suffered an odontoid fracture (Type II or III) than in patients who suffered a C-2 complex fracture, hangman's fracture, or other $C-2$ fracture (chi-square test, $p=0.030$ ). Data are expressed as the percentage of patients with subaxial autofusion within each C-2 fracture classification. comparison of odontoid fractures (Types II and III) to all other fracture types combined revealed a higher occurrence of subaxial autofusion among patients who suffered an odontoid fracture $(\mathrm{p}=0.002)$.

All fracture groups were predominately treated nonoperatively (Type II odontoid, 54\%; C-2 complex, 78\%; Type III odontoid, 87\%; hangman's, 63\%; and other, $43 \%$ ). Management with a cervical collar was the most frequently used nonoperative treatment among all fracture patterns. However, treatment modalities differed between fracture patterns (Table 3, p < 0.001; Table 4, p = 0.023). In particular, operative management for Type II odontoid fractures was more common compared with all other fracture groups combined $(\mathrm{p}=0.002)$. Five patients with Type II odontoid fractures required a secondary procedure following the failure of the initial treatment; 1 collar was converted to a posterior fusion, whereas 3 were converted to anterior odontoid screws, and 1 patient treated initially in a halo vest device was converted to a posterior fusion. Two patients with a C-2 complex fracture were converted to secondary treatment; one from a collar to a halo vest device, and the other from an anterior screw to posterior fusion.

There was no difference between fracture groups with 
TABLE 4. Operative and nonoperative treatment of 127 C-2 fracture types

\begin{tabular}{lccccccc}
\hline \multicolumn{1}{c}{ Treatment } & Overall Cohort & Type II Odontoid* & C-2 Complex & Type III Odontoid & Hangman's & Other & $p$ Value \\
\hline Op & $39(30.7)$ & $33(42.9)$ & $3(12.5)$ & $0(0)$ & $3(30.0)$ & $0(0)$ & 0.002 \\
\hline Nonop & $88(69.3)$ & $44(57.1)$ & $21(87.5)$ & $13(100)$ & $7(70.0)$ & $3(100)$ & \\
\hline Management type & & & & & & \\
\hline Anterior approach & $22(17.3)$ & $22(28.6)$ & $2(8.3)$ & $0(0)$ & $0(0)$ & $0(0)$ \\
\hline Posterior approach & $14(11.0)$ & $11(14.3)$ & $1(4.2)$ & $0(0)$ & $3(30.0)$ & $0(0)$ \\
\hline Halo & $11(8.7)$ & $5(6.5)$ & $3(12.5)$ & $0(0)$ & $1(10.0)$ & $0(0)$ \\
\hline Collar & $80(63.0)$ & $39(50.6)$ & $18(75.0)$ & $13(100)$ & $6(60.0)$ & $3(100)$ \\
\hline
\end{tabular}

Values are expressed as the number of cases (\%). Cases of the 14 patients who died before treatment or whose treatment is unknown are excluded.

* For Type II odontoid fractures, 1 case treated in a collar was converted to posterior fusion, and 2 cases treated in a halo were converted to anterior screw.

regard to mortality (Table $3, \mathrm{p}=0.186$ ). The 1-year mortality rate was $27 \%$ (38 of 141 patients). Eight patients died before treatment for their $\mathrm{C}-2$ fracture could be initiated. Two of these deaths were a direct result of a high complete spinal cord injury (SCI) associated with the C-2 fracture, 2 had care withdrawn, 2 suffered a myocardial infarction, and 2 died of other medical complications. Within 6 months of injury, 2 other patients died of complications arising from their SCI; these 2 were 95-year-olds who had American Spinal Injury Association (ASIA) Grade D central cord syndromes but declined operative treatment and progressively became quadriplegic. This resulted in a total of $4(3 \%)$ deaths directly related to an SCI. All 4 of these deaths occurred in patients who suffered an odontoid fracture, 3 of which were Type II odontoid fractures. Otherwise, the majority of deaths were associated with secondary causes not directly related to the C-2 fracture (34 of 38 deaths). The most frequent secondary causes of death included respiratory complications in 9 patients, cardiovascular in 4 patients, and cancer in 4 patients. Five patients died of other secondary complications, and for 6 patients the cause of death was unknown. In a subanalysis of the mortality rate between operative and nonoperative treatment subgroups within each fracture group, the mortality rate was higher after nonoperative treatment than after operative treatment for Type II odontoid fractures ( $44 \%$ vs $20 \%, \mathrm{p}=0.048$; Table 5), excluding the patients who died before treatment and those who had unknown treatment.
Mortality rates did not differ between anterior approach, posterior approach, halo treatment, or collar treatment modalities within each fracture pattern.

\section{Discussion}

It is well recognized that the elderly are predisposed to cervical spine fractures, and in particular C-2 fractures. ${ }^{22}$ This study has demonstrated that although half of C-2 fractures are Type II odontoid fractures, the elderly commonly sustain Type III odontoid fracture, hangman's fracture, or a combination of both (complex) as well. Much literature has been published on the treatment of Type II odontoid fractures in the elderly, although differences in the approach to treatment remain unresolved..$^{3-5}$ $7,8,10,11,15,16,18,20,22$ In the largest retrospective review to date on this topic, Pearson et al. ${ }^{19}$ analyzed 53,338 patients in the Medicare population (older than 65 years) who had a C-2 fracture, but these investigators could not distinguish between fracture types using ICD-9 codes. Our findings suggest that half the population we analyzed did not have the Type II odontoid fracture type, which may confound the comparison of operative versus nonoperative management. Those who have considered types of C-2 fractures have done so using a subanalysis and their studies have involved a relatively small sample size. Sokolowski et al. ${ }^{23}$ conducted a descriptive subanalysis of 38 axial injuries among 193 cervical injuries in a retrospective review of

TABLE 5. Comparison of mortality rate between operative and nonoperative treatment

\begin{tabular}{|c|c|c|c|c|c|c|}
\hline Treatment & Overall Cohort & Type II Odontoid & C-2 Complex & Type III Odontoid & Hangman's & Other \\
\hline Op & $5 / 30(16.7)$ & $5 / 25(20.0)$ & $0 / 3(0)$ & $0 / 0(0)$ & $0 / 2(0)$ & $0 / 0$ \\
\hline Nonop & $22 / 73(30.1)$ & $16 / 36(44.4)$ & $2 / 19(10.5)$ & $2 / 9(22.2)$ & $1 / 6(16.7)$ & $1 / 3(33.3)$ \\
\hline Significance btwn op \& nonop management & $p=0.219$ & $p=0.048$ & $p=1.000$ & NA & $p=1.000$ & NA \\
\hline \multicolumn{7}{|l|}{ Management type } \\
\hline Anterior approach & 2/18 (11.1) & $2 / 16(12.5)$ & $0 / 2(0)$ & $0 / 0$ & $0 / 2(0)$ & $0 / 0$ \\
\hline Posterior approach & $3 / 12(25.0)$ & $3 / 9(33.3)$ & $0 / 1(0)$ & $0 / 0$ & $0 / 0(0)$ & $0 / 0$ \\
\hline Halo & $1 / 8(12.5)$ & $1 / 4(25.0)$ & $0 / 3(0)$ & $0 / 0$ & $0 / 1(0)$ & $0 / 0$ \\
\hline Collar & $21 / 65$ (32.3) & $15 / 32(46.9)$ & $2 / 16(12.5)$ & $2 / 9(22.2)$ & $1 / 5(20.0)$ & $1 / 3(33.3)$ \\
\hline Significance btwn management types & $p=0.263$ & $p=0.133$ & $p=1.000$ & NA & $p=1.000$ & NA \\
\hline
\end{tabular}

NA = not applicable.

Values are expressed as the number of cases (\%). Cases of the 14 patients who died before treatment was initiated or whose treatment or mortality status is unknown are excluded. 
prospectively collected data, but did not do a comparative analysis. Koller et al. ${ }^{12}$ assessed 35 patients with a C-2 fracture but evaluated identical morphological characteristics within C-2 fracture subtypes, such as intraarticular fracture pattern and number of main fragments. Daentzer and Flörkemeier ${ }^{5}$ reported the distribution of C-2 fractures in 29 patients younger and older than 65 years of age, but analyzed all fracture patterns together after halo vest treatment. Therefore, our study contributes to the literature an understanding of the patient demographics, fracture type distribution, and mortality rate for the remaining $50 \%$ of these less-studied fracture patterns.

Not surprisingly, we confirmed that the vast majority of C-2 fractures in the elderly population are sustained in a fall from a standing height. . $^{13,14,16,17}$ The high prevalence of standing-height falls leading to a C-2 fracture is thought to be associated with an increased stiffness of the motion segments in the subaxial cervical spine and a relative osteopenia in the upper cervical spine. ${ }^{13}$ We demonstrated a high prevalence of autofusion within the subaxial spine in all fracture patterns, but most commonly in odontoid fractures, validating a stiff spine as a risk factor predisposing to these injuries.

Because a fall from a standing height is the most common reason for fracture, we attempted to identify patient risk factors for falls as defined by the WHO. ${ }^{27}$ We identified several, and found that more than $65 \%$ of our patients had 3 or more risk factors for falling - the most common being polypharmacy and medical comorbidities. As advocated by gerontologists, these are potentially modifiable or preventable risk factors, which suggest an opportunity to reduce the likelihood of these fractures occurring. It is unknown whether our fracture cohort had more risk factors for falls when compared with an age-matched cohort of individuals without fractures. Having more risk factors for falls did not predispose to a higher mortality rate in our study, however.

Previous studies have summarized the controversy regarding surgical versus nonsurgical management of Type II odontoid fractures. ${ }^{3,4,7,11,15,18,22}$ However, there exists no consensus regarding to the best management of this fracture type. In our patient cohort we found that all fracture patterns were treated predominately with nonoperative management. However, operative management was used more frequently for patients with Type II odontoid fractures than other fracture types. The treatment of the patients in this retrospective study reflects the bias of the individual treating surgeon. There is no specific algorithm that was followed by the surgeons treating these patients. However, we believe that the 2 most important factors to consider when treating C-2 fractures in the elderly are fracture stability and patient premorbid health. ${ }^{11,27}$ Fracture stability was most commonly judged by severity of fracture malalignment and the propensity of the fracture to maintain "acceptable" alignment. Certainly, a plethora of radiographic measurements have been published assessing fracture translation, gap, pattern, and comminution, particularly with respect to odontoid fractures, to help determine this. ${ }^{2,9}$ If nonoperative treatment was selected, follow-up was vigilant to ensure that a mobile nonunion or significant canal stenosis did not occur. "Acceptable" alignment was dependent on patient comorbidity. This is in respect to not only perioperative risk for a significant medical complication and/or death but also prefracture functional demand from both a physical and mental health perspective. For example, in a severely demented 75-yearold patient, following appropriate family/decision maker consultation, a larger malalignment may be deemed "acceptable" than in an active, relatively healthy 85-year-old individual. Probably, the concern regarding spinal canal compromise with unstable Type II odontoid fractures led to the increased rate of surgery for this fracture type. This concern is consistent with the finding that 3 of the 4 deaths caused by an SCI occurred in Type II odontoid fractures.

Yet, only a small percentage of the deaths can be directly attributed to the C-2 fracture (i.e., SCI). The majority of deaths in the 1st year are a result of associated medical comorbidities. The 1-year mortality rate was $27 \%$. This is in agreement with previous studies that have suggested a 1-year mortality rate between $24 \%$ and $39 \% .^{3,4,10,17,19}$ In a subanalysis of the mortality rate between operative and nonoperative treatment within each fracture group, we found that the mortality rate was higher after nonoperative treatment than after operative treatment for Type II odontoid fractures (although no adjustment was made for potential confounders). This was similarly reported by the AOSpine North American Geriatric Odontoid Fracture Mortality Study, ${ }^{3}$ which did adjust for age, sex, and comorbidities. Likewise, Schoenfeld et al. ${ }^{21}$ reported a 1-year mortality rate (36\% vs $21 \%$ ) in favor of operative treatment $(n=44)$ compared with nonoperative treatment $(n=112)$. However, mortality was similar at a short-term survival period of 3 months. We did not identify an increased mortality level in any of our fracture groups compared with the others.

Our study shares the limitations common to all retrospective reviews; complete imaging was lacking, which resulted in the exclusion of patients from an otherwise consecutive series, and medical records were incomplete in some instances. The study results may also be influenced by selection bias because the surgeons determined treatment at their own discretion. The retrospective nature of this review precluded the reliable assessment of neurological and functional status at follow-up and thus it does not include rates of treatment-related adverse events (which should be collected prospectively to prevent underestimation ${ }^{26}$ ); we therefore are unable to reliably determine if these factors differ between fracture pattern groups. However, our study is one of the largest cohorts comparing types of C-2 fractures today. Despite this, the sample size remains small in each subgroup, which diminishes interpretability. Nevertheless, this study highlights the fact that nearly half of C-2 fractures sustained in elderly patients are not Type II odontoid fractures. Furthermore, we have defined a "complex" fracture pattern, which is more common to the female sex and, similarly to the Type III odontoid fracture, can be considered relatively stable and treated nonoperatively.

\section{Conclusions}

Although not as common as Type II odontoid fractures, other C-2 fractures including hangman's, complex, and 
Type III odontoid fractures accounted for close to half of the injuries in our study cohort. There were few differences between the fracture types with respect to cause of injury, predisposing factors, or mortality rate. However, surgical treatment was more common for Type II odontoid fractures.

\section{References}

1. Administration on Aging: A Profile of Older Americans: 2011. Washington, DC: US Department of Health and Human Services, 2014 (https://aoa.acl.gov/Aging_Statistics/ Profile/2011/index.aspx) [Accessed April 25, 2017]

2. Anderson LD, D'Alonzo RT: Fractures of the odontoid process of the axis. J Bone Joint Surg Am 56:1663-1674, 1974

3. Chapman J, Smith JS, Kopjar B, Vaccaro AR, Arnold P, Shaffrey CI, et al: The AOSpine North America Geriatric Odontoid Fracture Mortality Study: a retrospective review of mortality outcomes for operative versus nonoperative treatment of 322 patients with long-term follow-up. Spine (Phila Pa 1976) 38:1098-1104, 2013

4. Chen YR, Boakye M, Arrigo RT, Kalanithi PS, Cheng I, Ala$\min \mathrm{T}$, et al: Morbidity and mortality of $\mathrm{C} 2$ fractures in the elderly: surgery and conservative treatment. Neurosurgery 70:1055-1059, 2012

5. Daentzer D, Flörkemeier T: Conservative treatment of upper cervical spine injuries with the halo vest: an appropriate option for all patients independent of their age? J Neurosurg Spine 10:543-550, 2009

6. Damadi AA, Saxe AW, Fath JJ, Apelgren KN: Cervical spine fractures in patients 65 years or older: a 3-year experience at a level I trauma center. J Trauma 64:745-748, 2008

7. Delcourt T, Bégué T, Saintyves G, Mebtouche N, Cottin P: Management of upper cervical spine fractures in elderly patients: current trends and outcomes. Injury 46 (Suppl 1):S24-S27, 2015

8. Elgafy H, Dvorak MF, Vaccaro AR, Ebraheim N: Treatment of displaced Type II odontoid fractures in elderly patients. Am J Orthop 38:410-416, 2009

9. Francis WR, Fielding JW, Hawkins RJ, Pepin J, Hensinger R: Traumatic spondylolisthesis of the axis. J Bone Joint Surg Br 63-B:313-318, 1981

10. Harris MB, Reichmann WM, Bono CM, Bouchard K, Corbett KL, Warholic N, et al: Mortality in elderly patients after cervical spine fractures. J Bone Joint Surg Am 92:567-574, 2010

11. Huybregts JG, Jacobs WC, Vleggeert-Lankamp CL: The optimal treatment of Type II and III odontoid fractures in the elderly: a systematic review. Eur Spine J 22:1-13, 2013

12. Koller H, Acosta F, Forstner R, Zenner J, Resch H, Tauber M, et al: C2-fractures: Part II. A morphometrical analysis of computerized atlantoaxial motion, anatomical alignment and related clinical outcomes. Eur Spine J 18:1135-1153, 2009

13. Lieberman IH, Webb JK: Cervical spine injuries in the elderly. J Bone Joint Surg Br 76:877-881, 1994

14. Lomoschitz FM, Blackmore CC, Mirza SK, Mann FA: Cervical spine injuries in patients 65 years old and older: epidemiologic analysis regarding the effects of age and injury mechanism on distribution, type, and stability of injuries. AJR Am J Roentgenol 178:573-577, 2002

15. Maak TG, Grauer JN: The contemporary treatment of odontoid injuries. Spine (Phila Pa 1976) 31 (11 Suppl):S53-S61, 2006

16. Majercik S, Tashjian RZ, Biffl WL, Harrington DT, Cioffi WG: Halo vest immobilization in the elderly: a death sentence? J Trauma 59:350-358, 2005

17. Ngo B, Hoffman J, Mower W: Cervical spine injury in the very elderly. Emerg Radiol 7:287-291, 2000
18. Omeis I, Duggal N, Rubano J, Cerabona F, Abrahams J, Fink M, et al: Surgical treatment of C2 fractures in the elderly: a multicenter retrospective analysis. J Spinal Disord Tech 22:91-95, 2009

19. Pearson AM, Martin BI, Lindsey M, Mirza SK: C2 vertebral fractures in the Medicare population: incidence, outcomes, and costs. J Bone Joint Surg Am 98:449-456, 2016

20. Rockswold GL, Bergman TA, Ford SE: Halo immobilization and surgical fusion: relative indications and effectiveness in the treatment of 140 cervical spine injuries. J Trauma 30:893-898, 1990

21. Schoenfeld AJ, Bono CM, Reichmann WM, Warholic N, Wood KB, Losina E, et al: Type II odontoid fractures of the cervical spine: do treatment type and medical comorbidities affect mortality in elderly patients? Spine (Phila Pa 1976) 36:879-885, 2011

22. Smith HE, Kerr SM, Fehlings MG, Chapman J, Maltenfort M, Zavlasky J, et al: Trends in epidemiology and management of type II odontoid fractures: 20 -year experience at a model system spine injury tertiary referral center. J Spinal Disord Tech 23:501-505, 2010

23. Sokolowski MJ, Jackson AP, Haak MH, Meyer PR Jr, Szewczyk Sokolowski M: Acute outcomes of cervical spine injuries in the elderly: atlantaxial vs subaxial injuries. J Spinal Cord Med 30:238-242, 2007

24. Spivak JM, Weiss MA, Cotler JM, Call M: Cervical spine injuries in patients 65 and older. Spine (Phila Pa 1976) 19:2302-2306, 1994

25. Statistics Canada: Population Count and Population Growth in Canada. Ottawa: Statistics Canada, 2015 (http://www.statcan.gc.ca/pub/91-520-x/2010001/aftertocaprestdm1-eng.htm) [Accessed April 25, 2017]

26. Street JT, Lenehan BJ, DiPaola CP, Boyd MD, Kwon BK, Paquette SJ, et al: Morbidity and mortality of major adult spinal surgery. A prospective cohort analysis of 942 consecutive patients. Spine J 12:22-34, 2012

27. Todd C, Skelton D: What Are the Main Risk Factors for Falls Among Older People and What Are the Most Effective Interventions to Prevent These Falls? Copenhagen: World Health Organization, 2004 (http://www. euro.who.int/__data/assets/pdf_file/0018/74700/E82552.pdf) [Accessed April 25, 2017]

28. Watanabe M, Sakai D, Yamamoto Y, Sato M, Mochida J: Upper cervical spine injuries: age-specific clinical features. J Orthop Sci 15:485-492, 2010

\section{Disclosures}

The authors report no conflict of interest concerning the materials or methods used in this study or the findings specified in this paper.

\section{Author Contributions}

Conception and design: Bailey, Radovanovic, Siddiqi. Acquisition of data: Bailey, Radovanovic, Rasoulinejad. Analysis and interpretation of data: Bailey, Radovanovic, Urquhart, Rasoulinejad. Drafting the article: Radovanovic, Urquhart. Critically revising the article: all authors. Reviewed submitted version of manuscript: all authors. Approved the final version of the manuscript on behalf of all authors: Bailey. Statistical analysis: Urquhart. Administrative/technical/material support: Radovanovic, Urquhart. Study supervision: Bailey.

\section{Correspondence}

Christopher S. Bailey, London Health Sciences Center, E4-117, 800 Commissioners Rd. East, London, ON N6A 4G5, Canada. email: chris.bailey@1hsc.on.ca. 